\title{
Bericht über die Chicago Ophthalmological Society
}

\section{Sitzung vom 13. März 1906}

Von

R. DENIG,

New York.

Suker berichtet über folgenden Fall:

Bei einem 21jährigen Manne entwickelte sich infolge Explosion eines Perkussionsschlosses eine sero-plastische Iridocyklitis.

Um grösste Dilatation der Pupille zu erzielen, wurde Dionin in Pulver-form in den

Bindehautsack gebracht. Unerwarteterweise entwickelte sich eine exzessive Myosis. Die

Pupillenöffnung war kaum sichtbar, und selbst Atropin brachte erst nach Stunden eine

stecknadelkopfgrosse Erweiterung

398

Gesellschaftsberichte.

zu stande. Zwei Tage später, nachdem jegliche Reizung des Auges ver-schwunden war, wurde eine Iridektomie ausgeführt, und es stellte sich heraus, das"s innerhalb dieser kurzen Zeit eine Verlötung der Hinterfläche der Regenbogenhaut mit der vorderen Linsenkapsel stattgetunden hatté. Es drängte 1/8ich die Frage auf, war die Myosis das Resultat einer Idiosynkrasie des Patienten oder einer unreinen Herstellung des (Dionin) Präparates.

Es wurde desbalb dasselbe Pulver bei einem anderen Patienten probiert, der auch an Iridocyklitis litt, ohne dass es jedoch eine ungewöhnliche Wirkung ausübte.

In der Diskussion bericlitet eine Reihe von Beobachtern über äbnliche Erfahrungen.

Bei der Behandlung von Trachom benutzt Remmen das zugespitzte Ende eines Zahnstochers, um die Follikel zu öffnen und zu entleeren; bíerauf wendet er eine $1: 5000$ Sublimatlösung an.

Fiske konstatiert, dass er seit 15 Jahren bei der Behandlung von Trachom weder Arg. nit., noch Kupfer angewandt habe.

Gamble stellte einen Fall von diabetischer Retinitis vor.

Suker fragt in der Diskussion an, ob der Blutdruck gemessen wurde. Diabetes stellt eine Toxämie dar und alle Toxämien erhöhen den Blutdruck, entweder lokal oder allgemein. Betor die spezifischen Lãsionen in der Netzhaut erscheinen, kann man immer eine hauchige Trübung der Netzhaut konstatieren, eine Folge des erhöhten peripheren Blutdrucks. Je holier der Blutdruck, um so leichter kommt es zu Blutungen und vice versa. 1st der Blutdruck niedrig, so treten mehr die entzündlichen Symptome in den Vordergrund.

Ẃilders Patient zeigte die Symptome einer hyalinen Degeneration der Bindehaut. Wiederholte operative Eingriffe hatten keinen wesent-iichen Erfolg.

Colorado Ophthalmological Society.

Sitzung vom 17. Februar 1906.

Black stellte folgenden Fall vor:

Infolge Dynamitexplosion im September 1904 hatte der Patient das linke Auge verloren. Das rechte Auge zeigte eine sehr feine Wunde im Hornhautrande. Eine korrespondierende Oefi ${ }^{\circ}$ nung 
konnte in der Regenbogenhaut nachgewiesen werden, ferner eine feine Linsen- und Glaskörpertrübung und eine punktförmige Blutung nahe dem nasalen Sehnervenrande. Etwas nach vorn und nasal von der Glaskörpermitte befand sich ein kleines Kupfer-stückchen. In letzter Zeit veränderte der Fremdkörper plötzlich seinen Sitz und verschwand wahrscheinlich hinter dem Ciliarkörper. Die Sehkraft war dabei normal.

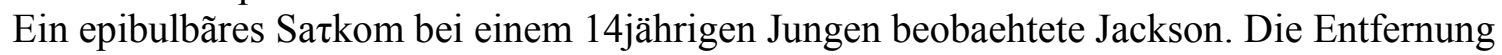
wurde mit lokaler Anästhesie - Kokainkristalle - vorgenommen. Hierbei zeigte sich, dass die Geschwulst mit der Sklera adhärent war. Es musste deshalb an dieser Stelle ein grösserer Teil der Sklera geopfert werden, so dass sie beinahe perforiert werden musste. Weder von seiten der Aderhaut, noch des Strahlenkörpers kam es zur Blutung, auch blieb der Binnendruck des Auges normal. Nach 16 Tagen war die Wundfläche von dichtem Granulationsgewebe gefüllt. Bei einem Hornhautgeschwür benutzte Bane eine starke - nahezu reine - Lösung von_Alpliozon. Es stellte sich sofort heftiger Schmerz ein. Das Auge wurde gleich ausgewaschen und trikresolisiertes Vaselin $(1: 1000)$ eingestrichen. Es genügte noch ein weiteres Anwenden von Alphozon, um das Geschwür zur Heilung zu bringen. Atropin wurde selbstverständlich auch eingeträufelt.

L. Libby beobachtete eine membränöse Konjunktivitis. Die bakterio-logische Untersuchung wies Xerosebazillen in Ueberfluss áuch Strepto- und Staphylokokken nach aber keine Diphtheriebazillen. Nebenbei bestand bei dem áOjährigen Patienten eine Uveitis. 